\title{
PEMBERDAYAAN KELUARGA SADAR HIPERTENSI (GADARSI) DALAM PENINGKATAN GAYA HIDUP SEHAT PENDERITA HIPERTENSI
}

\author{
Reni Zulfitri ${ }^{1}$, Ganis Indriati ${ }^{2}$, Yufitriana Amir ${ }^{3}$, Fathra Annis Nauli ${ }^{4}$ \\ 1,2,3,4 Fakultas Keperawatan Universitas Riau Jalan Pattimura No 9 Gedung G Pekanbaru Riau \\ Kode Pos 28131 Indonesia \\ E-mail : renz_emi@yahoo.com
}

\begin{abstract}
Abstrak
Hipertensi adalah salah satu jenis penyakit tidak menular yang bersifat kronis, berlangsung sepanjang hayat dan bersifat silent killer, dengan angka prevalensi yang sangat tinggi khususnya pada usia dewasa dan lansia. Oleh karena itu, penting sekali peran keluarga dalam mencegah terjadinya komplikasi akibat kondisi hipertensi yang tidak terkontrol melalui gaya hidup sehat sehari-hari. Penelitian ini bertujuan untuk mengetahui pengaruh pemberdayaan keluarga terhadap gaya hidup sehat penderita hipertensi. Penelitian ini dilakukan di Kecamatan Balai Jaya Kabupaten Rokan Hilir, dengan jumlah sampel sebanyak 35 orang dengan teknik purposive sampling. Desain penelitian ini adalah Quasi eksperiman. Hasil menunjukkan terjadi peningkatan gaya hidup sehat sebesar: 91,08\% (Pre test: 31,4\% dan post test: 60\%) dan hasil uji Wilcoxon menunjukkan terdapat pengaruh pemberdayaan keluarga terhadap gaya hidup sehat penderita hipertensi dengan $\mathrm{p}$ value: 0,025 . Dengan demikian penting sekali upaya pemberdayaan keluarga dalam meningkatkan gaya hidup sehat penderita hipertensi di rumah.
\end{abstract}

Kata Kunci: Pemberdayaan keluarga, hipertensi, gaya hidup sehat

\begin{abstract}
Hypertension is a type of non-communicable disease that is chronic, lasts a lifetime and is a silent killer, with a very high prevalence, especially in adulthood and the elderly. Therefore, it is very important the role of the family in preventing complications due to uncontrolled hypertension through a healthy daily lifestyle. The purpose of this study was to determine the effect of family empowerment on healthy lifestyles of people with hypertension. This research was conducted in Balai Jaya District, Rokan Hilir Regency, with a total sample of 35 people with purposive sampling technique. The design of this study is Quasi experiment. The results showed an increase in healthy lifestyles by: $91.08 \%$ (Pre test: $31.4 \%$ and post test: $60 \%$ ) and Wilcoxon test results showed there was an influence of family empowerment on healthy lifestyles of hypertensive patients with $p$ value: 0.025 . Thus it is very important to empower the family in improving the healthy lifestyle of hypertension sufferers at home.
\end{abstract}

Keywords: family empowerment, hypertension, healthy lifestyle

\section{PENDAHULUAN}

Hipertensi adalah salah satu jenis penyakit tidak menular yang bersifat kronis, berlangsung sepanjang hayat dan bersifat silent killer, dengan angka prevalensi yang sangat tinggi khususnya pada lansia. Di tingkat dunia terutama di negara maju, prevalensi hipertensi pada populasi lansia > 60 tahun diperkirakan mencapai dua pertiga atau sekitar $60 \%-80 \%$ (Giudice et al., 2010; Cornwell \& Waite, 2012). Kecenderungan itu juga terjadi di Indonesia. Data laporan Riset Kesehatan Dasar (Riskesdas) tahun 2013, menunjukkan bahwa prevalensi hipertensi di Indonesia menempati urutan pertama jenis penyakit kronis tidak menular yang dialami pada kelompok usia 
Reni Zulfitri' ${ }^{1}$, Ganis Indriati ${ }^{2}$, Yufitriana Amir ${ }^{3}$, Fathra Annis Nauli ${ }^{4}$, Pemberdayaan Keluarga Sadar Hipertensi (GADARSI) dalam Peningkatan Gaya Hidup Sehat Penderita Hipertensi

dewasa, yaitu sebesar 26,5\%. Prevalensi hipertensi di Indonesia cenderung meningkat seiring bertambahnya usia, yaitu prevalensi hipertensi pada kelompok usia 55-64 tahun sebesar 45,9\%; usia 65-74 tahun sebesar $57,6 \%$; dan kelompok usia $>75$ tahun sebesar 63,8\% (Kemenkes RI, 2013).

Hal yang sama juga terjadi di Provinsi Riau. Laporan Riskesdas tahun 2013 menunjukkan bahwa prevalensi hipertensi pada usia dewasa di Provinsi Riau sebesar 20,9\% dan prevalensi hipertensi tersebut cenderung mengalami peningkatan seiring bertambahnya usia. Di Provinsi Riau, prevalensi hipertensi pada kelompok usia 5564 tahun sebesar 45,6\%; kelompok usia 65-74 tahun sebesar 61,8\%; dan kelompok usia 75 tahun ke atas sebesar 72,5\% (Kemenkes RI, 2013).

Penyakit hipertensi merupakan urutan pertama jenis penyakit kronis tidak menular yang dialami oleh kelompok usia lanjut di Provinsi Riau (Dinkes Provinsi Riau, 2016). Dengan demikian, terlihat bahwa hipertensi merupakan masalah kesehatan umum pada lansia dan menjadi fokus pelayanan kesehatan masyarakat di dunia, termasuk di Indonesia, termasuk di Provinsi Riau.

Hal yang menjadi persoalan adalah berbagai hasil studi menunjukkan bahwa tingginya prevalensi hipertensi tersebut diiringi dengan tingginya kondisi hipertensi yang tidak terkontrol di dunia, termasuk di
Indonesia khususnya di Provinsi Riau, yaitu lebih dari 50\% (Guessous et al., 2012; Cornwell and Waite, 2012; \& Kemenkes RI, 2013). Kondisi itu dapat meningkatkan kejadian komplikasi akibat hipertensi yang tidak terkontrol, seperti: penyakit stroke dan jantung yang menjadi penyebab kematian utama pada lansia di tingkat dunia (Soyibo \& Barton, 2012; Seedat, Rayner, Veriava, 2014; Kjeldsen et al., 2014; dan Zhang, 2015). Oleh karena itu, Nkondjock and Bizome (2010) menyatakan bahwa hipertensi dikenal sebagai silent killer dan faktor utama terjadinya penyakit jantung, stroke, dan kematian pada usia lanjut.

Proporsi penyebab kematian kelompok lansia yang paling tinggi adalah penyakit stroke dan penyakit jantung (ischaemic heart diseases) sebagai akibat lanjut dari hipertensi (Kemenkes RI, 2013; Dinkes Provinsi Riau, 2014). Hal itu menunjukkan hipertensi merupakan permasalahan kesehatan serius dan sepanjang hayat yang harus segera diatasi.

Program kesehatan lansia di Indonesia masih belum berhasil sepenuhnya dalam mengontrol kesehatan lansia terutama mengontrol kondisi hipertensi lansia. Hal itu disebabkan upaya pemberdayaan keluarga dalam program kesehatan lansia belum optimal, yang mana masih menempatkan keluarga sebagai objek (penerima pelayanan kesehatan). Pada umumnya anggota keluarga belum dilibatkan atau diberdayakan secara 
aktif sebagai caregiver utama bagi lansia di rumah (Kemenkes RI, 2012). Kondisi tersebut mengakibatkan rendahnya kemampuan anggota keluarga dalam melakukan perawatan pada lansia hipertensi secara mandiri di rumah, terutama dalam mengontrol gaya hidup penderita sehari-hari.

Menurut Kjeldsen et al., (2014); dan Zhang (2015), hal yang paling pertama dan utama dalam mengontrol kondisi tekanan darah adalah melalui modifikasi gaya hidup. Gaya hidup sehat penderita hipertensi diantaranya adalah: tidak merokok, tidak mengkonsumsi alkohol, diet rendah garam, latihan atau olahraga teratur, hindari stress.

Beberapa hasil studi menunjukkan bahwa peran keluarga sangat penting dalam mengontrol perilaku sehat penderita hipertensi. Beberapa hasil penelitian juga menunjukkan bahwa terdapat hubungan antara dukungan keluarga terhadap status dan kondisi kesehatan, lama dan beratnya penyakit, kematian, kondisi tekanan darah yang terkontrol, pengendalian tekanan darah, kesejahteraan psikologis, perilaku sehat lansia, kepatuhan lansia dalam menjaga dan mematuhi segala yang dianjurkan oleh tenaga kesehatan profesional, harga diri, dan kualitas hidup lansia (Al-Kandari, 2011; Cornwell \& Waite, 2012; Lino et al., 2013; Rabiei et al., 2013; Mukti, 2013; \& Herlinah, Wiarsih, Rekawati, 2013 ).
Hasil studi pendahuluan di Kecamatan Balai Jaya Kabupaten Rokan Hilir, menunjukkan mayoritas (4 dari 5 orang) penderita hipertensi menunjukkan gaya hidup yang tidak sehat, seperti: merokok, tidak membatasi konsumsi garam, suka ikan asin, jarang bahkan tidak pernah berolahraga. Dimana $100 \%$ penderita tinggal bersama keluarga. Mayoritas keluarga tidak pernah memberikan perhatian atau perlakuan khusus kepada anggota keluarga yang mengalami hipertensi.

Berdasarkan uraian tersebut, maka kami tertarik melakukan penelitian tentang pemberdayaan keluarga sadar hipertensi dalam peningkatan gaya hidup sehat penderita hipertensi sehari-hari. Adapun tujuan penelitian ini adalah untuk mengetahui pengaruh pemberdayaan keluarga sadar hipertensi (GADARSI) terhadap peningkatan gaya hidup sehat penderita hipertensi.

\section{METODE}

Design penelitian yang digunakan adalah Quasi eksperimen dengan pendekatan pre test dan post test design. Lokasi kegiatan di lakukan di Desa kepenghuluan Pasir Putih kecamatan Balai Jaya Kabupaten Rokan hilir, dengan jumlah sampel adalah 35 keluarga dan penderita Hipertensi yang diambil melalui teknik purposive sampling berdasarkan kriteria inklusi. 
Reni Zulfitri ${ }^{1}$, Ganis Indriati ${ }^{2}$, Yufitriana Amir ${ }^{3}$, Fathra Annis Nauli ${ }^{4}$, Pemberdayaan Keluarga Sadar Hipertensi (GADARSI) dalam Peningkatan Gaya Hidup Sehat Penderita Hipertensi

Proses pengumpulan data tentang gaya hidup penderita dilakukan sebelum intervensi dan sesudah intervensi dilakukan melalui kuesioner dan observasi ke rumah keluarga. Bentuk Intervensi pemberdayaan keluarga yang dilakukan adalah: memberikan pendidikan kesehatan kepada keluarga tentang pencegahan dan perawatan hipertensi, memberdayaan keluarga melakukan follow up atau monitoring evaluasi gaya hidup penderita hipertensi sehari-hari selama 2 bulan.

Instrumen atau alat ukur yang digunakan dalam penelitian kuantitatif adalah dalam bentuk kuesioner dan pedoman observasi yang telah dinyatakan valid dan reliabel melalui uji uji korelasi dengan metoda Pearson Product Moment ( r).

Analisis statistik yang dilakukan peneliti tentang gambaran gaya hidup sebelum dan sesudah intervensi adalah dalam bentuk distribusi frekwensi dan persentasi, sedangkan untuk mengetahui pengaruh pemberdayaan keluarga terhadap gaya hidup mengunakan uji wilcoxon (data terdistribusi tidak normal) dengan program Statistical Product and Service Solution (SPSS).

\section{HASIL}

1. Hasil penelitian tentang gambaran gaya hidup penderita hipertensi sebelum dan sesudah intervensi dapat dilihat pada tabel 1.
Tabel. 1

Gambaran gaya hidup penderita hipertensi dan yang berisiko sebelum (pres test) dan sesudah (post test) intervensi

\begin{tabular}{cccccc}
\hline Kategori & \multicolumn{2}{c}{ Pre Test } & \multicolumn{2}{c}{ Post Test } & EFEK \\
\cline { 2 - 5 } & $\mathrm{n}$ & $\%$ & $\mathrm{n}$ & $\%$ & \\
\hline - Sehat & 11 & 31,4 & 21 & 60 & $91,08 \%$ \\
\hline - Tidak Sehat & 24 & 68,6 & 14 & 40 & \\
\hline Total: & 35 & 100 & 35 & 100 & \\
\hline
\end{tabular}

Berdasarkan tabel 1 menunjukkan bahwa terjadi peningkatan gaya hidup sehat sebesar: 91,08\% (Pre test: $31,4 \%$ dan post test: $60 \%$ )

2. Hasil penelitian tentang pengaruh pemberdayaan keluarga sadar hipertensi (GADARSI) terhadap gaya hidup sehat penderita hipertensi dapat dilihat pada table 2 berikut ini.

Tabel. 2

Pengaruh pemberdayaan keluarga sadar hipertensi (GADARSI) terhadap gaya hidup sehat penderita hipertensi

\begin{tabular}{|c|c|c|c|}
\hline VARIABEL & $\begin{array}{c}\text { MEAN } \\
\text { (SD) }\end{array}$ & $\begin{array}{l}\text { MED } \\
(\min - \\
\max )\end{array}$ & $p$ value \\
\hline $\begin{array}{l}\text { Gaya hidup } \\
\text { penderita hipertensi: } \\
-\quad \text { Sebelum } \\
\text { intervensi }\end{array}$ & $\begin{array}{l}0,69 \\
(0,471)\end{array}$ & $\begin{array}{l}1,00 \\
(0-1)\end{array}$ & 0,025 \\
\hline $\begin{array}{l}\text { Sesudah } \\
\text { intervensi }\end{array}$ & $\begin{array}{l}0,40 \\
(0,497)\end{array}$ & $\begin{array}{l}0,00 \\
(0-1)\end{array}$ & \\
\hline
\end{tabular}

Berdasarkan tabel 2 menunjukkan bahwa terdapat pengaruh pemberdayaan keluarga sadar hipertensi (GADARSI) terhadap gaya hidup penderita hipertensi sehari-hari dengan $p$ value 0,025 ( $p$ value $<0,05$. 


\section{PEMBAHASAN}

Berdasarkan

hasil

penelitian

menunjukkan bahwa gambaran gaya hidup sehat penderita hipertensi sebelum intervensi masih rendah yaitu hanya 31,4\%. Menurut Kjeldsen et al., (2014); dan Zhang (2015), hal yang paling pertama dan utama dalam mengontrol kondisi tekanan darah adalah melalui modifikasi gaya hidup. Gaya hidup sehat penderita hipertensi diantaranya adalah: tidak merokok, tidak mengkonsumsi alcohol, diet rendah garam, latihan atau olahraga teratur, hindari stress.

Hasil beberapa studi menunjukkan bahwa mayoritas penderita hipertensi adalah kelompok usia lanjut. Menurut Friedman (2006) dalam Potter dan Perry (2010), lansia cenderung mengalami berbagai masalah kesehatan yang bersifat holistik. Salah satu masalah kesehatan yang menonjol pada lansia dengan penyakit kronis adalah masalah psikososial dengan menunjukkan sikap harga diri rendah, tak acuh, pasrah, dan tidak takut akan realitas kematian. Sikap lansia tersebut dapat memengaruhi motivasi dan perilaku lansia dalam mengontrol kesehatannya.

Selain itu, hasil studi menunjukkan adanya anggapan dari lansia dan keluarga bahwa masalah hipertensi adalah masalah yang biasa dan normal bagi orang yang sudah tua sehingga memengaruhi motivasi lansia dalam mengontrolkan kesehatannya ke pelayanan kesehatan (Watson, 2003; Stanley \& Beare,
2007; Soesanto, 2010; Potter \& Perry, 2010). Apabila tidak diatasi dengan segera maka dapat menurunkan kualitas hidup lansia (Anderson and McFarlane, 2007; Stanley \& Beare, 2007; Dongre \& Deshmukh, 2012; Vilhena et al., 2014). Hal itu dapat memberikan beban bagi semua pihak, baik bagi diri lansia itu sendiri, keluarga, masyarakat, maupun Pemerintah.

Hasil penelitian tentang gaya hidup penderita hipertensi setelah intervensi terjadinya peningkatan menjadi $60 \%$. Sehingga dapat diketahui terjadi peningkatan gaya hidup penderita hipertensi sebesar 91,08\%. Dari hasil ini dapat diketahui bahwa keluarga mempunyai peranan yang sangat penting dalam mengontrol gaya hidup penderita hipertensi.

Selain itu, hasil penelitian ini menunjukkan bahwa terdapat pengaruh pemberdayaan keluarga terhadap gaya hidup penderita hipertensi sehari-hari $(\mathrm{p}$ value $=$ 0,025). Beberapa hasil studi menjelaskan bahwa keluarga merupakan sasaran pertama dan utama dalam manajemen perawatan penyakit kronis pada lansia (Stanley \& Beare, 2007; Potter \& Perry, 2010; Soesanto, 2010). Bagi setiap kelompok etnik, keluarga pada umumnya merupakan support system pertama dan utama bagi lansia (Stanley \& Beare, 2007; Potter \& Perry, 2010). Bahkan menurut budaya Melayu Riau, keluarga adalah tempat yang paling aman dan nyaman bagi lansia 
Reni Zulfitri ${ }^{1}$, Ganis Indriati ${ }^{2}$, Yufitriana Amir ${ }^{3}$, Fathra Annis Nauli ${ }^{4}$, Pemberdayaan Keluarga Sadar Hipertensi (GADARSI) dalam Peningkatan Gaya Hidup Sehat Penderita Hipertensi

untuk menghabiskan sisa hidup. Anak dikatakan durhaka jika tidak mampu mengasuh orang tuanya dengan baik di rumah (Thamrin \& Iskandar, 2009). Mahler et al., (2014) juga menyatakan bahwa rumah adalah tempat terbaik bagi lansia dalam meningkatkan kesehatannya.

\section{SIMPULAN}

Hasil penelitian menunjukkan bahwa terjadi peningkatan gaya hidup sehat pada penderita hipertensi sebesar: 91,08\% (Pre test atau sebelum intervensi: $31,4 \%$ dan post test atau sesudah intervensi: $60 \%$ )

Hasil penelitian dengan uji Wilcoxon menunjukkan bahwa terdapat pengaruh pemberdayaan keluarga sadar hipertensi (GADARSI) terhadap gaya hidup penderita hipertensi sehari-hari, dimana $p$ value $=0,025$ (p value < 0,05). Dapat disimpulkan bahwa keluarga merupakan support system utama bagi penderita hipertensi, yang dapat mendukung dalam upaya mengontrol gaya hidup sehat penderita sehari-hari di rumah.

\section{SARAN}

\section{a. Untuk Dinas kesehatan Kota Pekanbaru}

Diharapkan hasil penelitian ini dapat menjadi pedoman dalam pengembangan program kesehatan lansia maupun program penanggulangan penyakit tidak menular di tatanan pelayanan kesehatan tingkat 1 yaitu Puskesmas. Dimana program kesehatan yang dikembangkan harus mengikutsertakan keluarga dari penderita atau program pemberdayaan keluarga.

\section{b. Untuk Puskesmas}

Penting untuk mensupport dan memfasilitasi berbagai kegiatan promosi kesehatan dan menumbuh kembangkan kegiatan UKBM, seperti Posyandu PTM dan Posyandu lansia untuk mendekatkan pelayanan kesehatan kepada masyarakat setempat dengan mengutamakan pemberdayaan keluarga

\section{c. Untuk Ilmu Keperawatan}

Bahan tambahan dalam pengembangan ilmu keperawatan keluarga, komunitas dan keperawatan lansia terutama terkait pentingnya pemberdayaan keluarga dalam mempengaruhi perilaku sehat penderita penyakit kronis.

\section{DAFTAR PUSTAKA}

Al-Kandari, Y.Y. (2011). Relationship of Strength of Social Support and Frequency of Social Contact with Hypertension and General Health Status Among Older Adults in the Mobile Care Unit in Kuwait. J Cross Cult Gerontol, 26:175-187

Cornwell, E.Y., \& Waite, L.J. (2012). Social network resources and management of Hypertension. Journal of Health and Social Behavior,53(2): $215-231$

Dinas kesehatan Provinsi Riau. (2016). Profil kesehatan provinsi Riau 2013. Pekanbaru: Dinas kesehatan Prov. Riau

Giudice, A.D., Pompa, G., and Aucella, F. (2010). Hypertension in the elderly. JNEPHROL, 23 (S15): S61-S71

Gonzalez, D.L.I., Norris, S.A. (2013). Chronic Non-Communicable Disease and Healthcare Access in Middle-Aged and Older Women Living in Soweto, South Africa. PLOS ONE, Volume 8, Issue 10, e78800 
Guessous, I., Bochud, M., Theler, J.M., Gaspoz, J.M., \& Pechere Bertschi, A. (2012). 1999-2009 Trends in Prevalence, Unawareness, Treatment and Control of Hypertension in Geneva, Switzerland. PLOS ONE,7, 6: e39877

Herlinah., Wiarsih, W., \& Rekawati, E. (2013). Hubungan dukungan keluarga dengan perilaku lansia dalam pengendalian Hipertensi di Jakarta. Jurnal Keperawatan Komunitas, Vol: 1, No. 2: 108-115. Portalgaruda.org/article

Kementrian Kesehatan, RI. (2013). Buletin jendela data dan informasi kesehatan: Gambaran kesehatan lanjut usia di Indonesia. Jakarta: Pusat data dan informasi kesehatan Kementrian Kesehatan RI.

Kjeldsen, S., Mourad, J.J., Zhang, W., Feldman, R.D., Lisheng, L., Chern-En Chiang, C.E., Wu, Z., Li, W., \& Williams, B. (2014). Updated National and International Hypertension Guidelines: A Review of Current Recommendations. Drugs, 74: 20332051

Lino, V.T.S., Margareth C. Portela, M.C., Camacho, L.A.B., Atie, S., \& Lima, M.J.B. (2013). Assessment of Social Support and Its Association to Depression, Self-Perceived Health and Chronic Diseases in Elderly Individuals Residing in an Area of Poverty and Social Vulnerability in Rio de Janeiro City, Brazil. PLOS ONE, Volume 8, Issue 8, e71712.

Mukti, A.G. (2012). Strategi dan kebijakan pelayanan kesehatan lanjut usia di Indonesia: Memanusiakan lanjut usia, penuaan penduduk dan pembangunan di Indonesia. Yogyakarta: Surveymeter.

Nkondjock, A., \& Bizome, E. (2010). Dietary patterns associated with hypertension prevalence in the Cameroon defence forces. European Journal of Clinical Nutrition, 64, 1014-1021

Rabiei, L., Mostafavi, F., Masoudi, R., \& Hassanzadeh, A. (2013). The effect of family-based intervention on empowerment of the elders. $J E d u c$ Health Promot, 2: 24.

Soyibo, A.K., \& Barton, E.N. (2012). Evaluation and management of Hypertension in the elderly. West Indian Med J, 61 (9): 907

Seedat, Y.K., BL Rayner, B.L., \& Veriava, Y. (2014). South african hypertension practice guideline 2014.Cardiovascular Journal Of Africa, Volume 25, No 6

Zhang, P.Y. (2015). Review of new hypertension guidelines. European Review for Medical and Pharmacological Sciences, 19: 312-315 